\title{
Early Post-cooling Brain Magnetic Resonance for the Prediction of Neurodevelopmental Outcome in Newborns with Hypoxic-Ischemic Encephalopathy
}

\author{
Mario Mastrangelo, Giulia Di Marzo ${ }^{1}$,Flavia Chiarotti², Chiara Andreoli’, Maria Chiara Colajacomo³, Anna Ruggieri ${ }^{1}$, \\ Paola Papoff ${ }^{1}$
}

Division of Pediatric Neurology, Department of Human Neurosciences, Sapienza University of Rome, ${ }^{1}$ Pediatric Intensive Care Unit, Department of Pediatrics, Child Neurology and Psychiatry, Sapienza University of Rome, ${ }^{2}$ Department of Cell Biology and Neuroscience, National Institute of Health and ${ }^{3}$ Emergency Radiology Unit, Department of Emergency and Acceptance, Sapienza University of Rome, Rome, Italy
Aim and Objectives: This study aimed to evaluate the predictive role of early post-cooling brain magnetic resonance for developmental outcome in newborns with hypoxic-ischemic encephalopathy. Materials and Methods: A retrospective cohort study was performed on 29 consecutive patients through magnetic resonance evaluation (visual analysis of the images and scoring of the detected lesions; mean diffusivity of semioval centre and lenticular nuclei; and area under the curve of basal ganglia $N$-acetylaspartate at proton magnetic resonance spectroscopic imaging) and Griffiths Mental Development Scales-third edition at 12 and 24 months. Results: Brain magnetic resonance was performed at a mean age of $5.7 \pm 3.7$ days. Newborns with no/minor magnetic resonance abnormalities had a better developmental outcome than patients with moderate or severe lesions. Structural and spectroscopic abnormalities in basal ganglia resulted in the most significant predictors for an unfavorable outcome. Conclusion: Normal magnetic resonance in early post-cooling phases is strongly associated with a favorable developmental outcome.

KEYWORDS: Development, hypoxic-ischemic encephalopathy, magnetic resonance, newborns, therapeutic hypothermia

\section{BACKGROUND}

$\mathcal{L}$ he use of brain magnetic resonance (MRI) developmental outcome in newborns with hypoxicischemic encephalopathy treated with therapeutic hypothermia has obtained a growing importance for the planning of posttreatment intensive care decisions and rehabilitation strategies. ${ }^{[1-7]}$

The literature is controversial about the optimal timing of neuroimaging for a reliable prediction power. ${ }^{[8-12]}$ In the pre-hypothermia era, some authors suggested that an early-performed brain MRI (first week after birth) could underestimate the presence and the extension of brain lesions and that the outcome could be better evaluated through scans obtained in later stages

Received: 11-02-19, Revised: 04-09-19, Accepted: 04-09-19,

Published: 05-12-19

\section{Access this article online}

Quick Response Code:

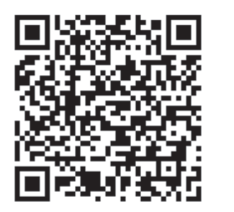

Website:

www.pediatricneurosciences.com

DOI: 10.4103/jpn.JPN_25_19 (between the second week and the first month after birth). ${ }^{[2]}$ A different orientation emerges from the few available studies in newborns treated with hypothermia who had received a complete developmental evaluation within the age of 24 months. ${ }^{[6,13-15]}$ Charon et al.,,$^{[7]}$ in particular, observed in 29 patients that early-performed brain MRI (between 1 and 6 days after birth) had the same sensitivity for adverse outcomes $(100 \%)$ and a higher specificity ( $96.3 \%$ vs. $89.3 \%$ ) than late-performed MRI (between 9 and 21 days after birth). Other authors reported similar data, despite relevant methodological differences in the MRI parameters that were used to

Address for correspondence: Dr. Mario Mastrangelo, Child Neurology and Psychiatry Unit, Department of Human Neurosciences, Sapienza University of Rome, Via dei Sabelli, 108-00185 Rome, Italy. E-mail: mario.mastrangelo@uniroma1.it

This is an open access journal, and articles are distributed under the terms of the Creative Commons Attribution-NonCommercial-ShareAlike 4.0 License, which allows others to remix, tweak, and build upon the work non-commercially, as long as appropriate credit is given and the new creations are licensed under the identical terms.

For reprints contact: reprints@medknow.com

How to cite this article: Mastrangelo M, Di Marzo G, Chiarotti F, Andreoli C, Colajacomo MC, Ruggieri A, et al. Early post-cooling brain magnetic resonance for the prediction of neurodevelopmental outcome in newborns with hypoxic-ischemic encephalopathy. J Pediatr Neurosci 2019;14:191-202. 
define the severity of brain lesions and in the cognitive and motor scales that were used for the evaluation of developmental outcome. ${ }^{[13-15]}$ All these papers were focused on isolated neuroradiological biomarkers (structural, diffusivity, or spectroscopic data were analyzed separately in different samples). ${ }^{[6,7,13-15]}$

This study aimed to evaluate, in a common sample, the prognostic role of main structural, diffusivity, and spectroscopic indices at brain MRI in the early stages after therapeutic hypothermia for the prediction of developmental outcome.

\section{Materials and Methods}

All patients with hypoxic-ischemic encephalopathy, who had received therapeutic hypothermia (whole body cooling) in the neonatal age in the Pediatric Intensive Care Unit of the Department of Pediatrics, Child Neurology and Psychiatry at "Sapienza"-University of Rome between January 1, 2011 and December 31, 2015, were enrolled for a retrospective cohort study when both a post-cooling MRI and a complete neurological and neuropsychological follow-up lasting more than two years were available.

In our institutional protocol, the realization of brain MRI was forecasted at the fourth day after birth (after the end of therapeutic hypothermia). MRI was anticipated in newborns with specific indications (i.e., worsening seizures or suspect of cerebral hemorrhage before the fourth day after birth) and postponed in patients whose clinical conditions were not stable enough for a safe transport to our Radiology Section (i.e., patients under nitric oxide).

Brain MRI examinations were performed with $1.5 \mathrm{~T}$ Siemens Avanto, Erlangen, Germany, including superconductive magnets (six-channel coil) performing single, multiple, and volumetric acquisitions (sequences GRE, IR, STIR, FLAIR, SSFSE, MTC, and EPI; layer thickness: $0.1-2 \mathrm{~mm}$; matrix: $256 \times 512$ ). Diffusionweighted images (DWI) was obtained using a singleshot, echoplanar imaging sequence with diffusion

\begin{tabular}{|c|c|c|c|c|c|c|c|c|c|c|}
\hline Patient & Sex & $\begin{array}{l}\text { Gestational } \\
\text { age (weeks) }\end{array}$ & $\begin{array}{c}\text { Birth } \\
\text { weight (g) }\end{array}$ & $\begin{array}{c}\text { Apgar } \\
\text { score 1' }\end{array}$ & $\begin{array}{l}\text { Apgar } \\
\text { score 5' }\end{array}$ & $\begin{array}{c}\text { Apgar score } \\
10^{\prime}\end{array}$ & $\begin{array}{l}\text { Sarnat } \\
\text { stage }\end{array}$ & pH & $\mathbf{B E}$ & $\begin{array}{c}\text { aEEG (according to } \\
\text { Al Naqueeb et al.'s } \\
\text { classification) }\end{array}$ \\
\hline 1 & $\mathrm{~F}$ & 36.5 & 2600 & 4 & 7 & I & 2 & 7.09 & -18.8 & Moderately abnormal \\
\hline 2 & M & 40 & 3110 & 3 & 7 & l & 2 & 6.98 & -21.9 & Moderately abnormal \\
\hline 3 & $\mathrm{~F}$ & 39.7 & 3450 & 3 & 4 & 8 & 2 & 7.24 & -16.7 & Moderately abnormal \\
\hline 4 & M & 41.1 & 3440 & 2 & 7 & 1 & 3 & 7.12 & -20.7 & Moderately abnormal \\
\hline 5 & M & 39 & 3300 & 3 & Intubation & Intubation & 3 & 6.93 & -25 & Moderately abnormal \\
\hline 6 & $\mathrm{~F}$ & 38 & 3000 & 3 & 6 & 7 & 2 & 6.80 & -27 & Moderately abnormal \\
\hline 7 & M & 37.5 & 3150 & 0 & 3 & Intubation & 3 & 6.90 & -20 & Moderately abnormal \\
\hline 8 & $\mathrm{~F}$ & 41 & 2950 & 0 & 4 & 7 & 2 & 6.9 & -19 & Moderately abnormal \\
\hline 9 & M & 39 & 4020 & 5 & 7 & I & 2 & 7.22 & -8.6 & Moderately abnormal \\
\hline 10 & $\mathrm{~F}$ & 38 & 2700 & 4 & 6 & Intubation & 3 & 7.06 & -15 & Severely abnormal \\
\hline 11 & $\mathrm{~F}$ & 37 & 3100 & 5 & 8 & 1 & 2 & 7.17 & -10.7 & Moderately abnormal \\
\hline 12 & M & 40 & 2960 & 1 & 5 & 8 & 2 & 7.13 & -19.9 & Moderately abnormal \\
\hline 13 & $\mathrm{~F}$ & 39.8 & 2860 & 2 & 5 & I & 2 & 6.90 & -23 & Moderately abnormal \\
\hline 14 & M & 37.7 & 3770 & 1 & 5 & 8 & 2 & 6.96 & -24 & Moderately abnormal \\
\hline 15 & M & 42.4 & 3985 & 2 & 5 & Intubation & 3 & 6.80 & -14.8 & Moderately abnormal \\
\hline 16 & $\mathrm{~F}$ & 35.8 & 2290 & 5 & 7 & 8 & 2 & 7.10 & -13 & Moderately abnormal \\
\hline 17 & $\mathrm{~F}$ & 40.3 & 3510 & 3 & 7 & 1 & 2 & 7.30 & -8.5 & Moderately abnormal \\
\hline 18 & $\mathrm{~F}$ & 40.7 & 3200 & 1 & 4 & Intubation & 2 & 7.06 & -29 & Moderately abnormal \\
\hline 19 & M & 34 & 2570 & 0 & 3 & Intubation & 3 & 6.80 & -31 & Severely abnormal \\
\hline 20 & $\mathrm{~F}$ & 38 & 2700 & 1 & 4 & 7 & 2 & 6.86 & -22.7 & Severely abnormal \\
\hline 21 & $\mathrm{~F}$ & 40 & 2900 & 1 & 4 & Intubation & 3 & 7.04 & -17 & Severely abnormal \\
\hline 22 & M & 40 & 2800 & 4 & 8 & 8 & 2 & 7.30 & -6.7 & Moderately abnormal \\
\hline 23 & M & 40 & 2900 & 2 & 5 & Intubation & 2 & 7.29 & -13 & Severely abnormal \\
\hline 24 & $\mathrm{~F}$ & 38.2 & 2480 & 3 & Intubation & Intubation & 3 & 7.23 & -17.5 & Severely abnormal \\
\hline 25 & M & 40 & 3820 & 1 & 4 & 6 & 2 & 7.20 & -14 & Moderately abnormal \\
\hline 26 & M & 40.5 & 2670 & 4 & 8 & 8 & 2 & 7.28 & -12 & Moderately abnormal \\
\hline 27 & $\mathrm{~F}$ & 40 & 3200 & 1 & 5 & 7 & 2 & 7.24 & -9 & Moderately abnormal \\
\hline 28 & M & 39 & 2950 & 5 & 8 & 8 & 2 & 7.10 & -22.1 & Moderately abnormal \\
\hline 29 & M & 39 & 3950 & 6 & 8 & 10 & 2 & 7.14 & -16.7 & Moderately abnormal \\
\hline
\end{tabular}

aEEG $=$ amplitude-integrated electroencephalography, $\mathrm{BE}=$ base excess 
sensitization obtained in 3-12 different directions and $b$-values of 0 and $1.000 \mathrm{~s} / \mathrm{mm}^{2}$. HM spatial resolution was $1.5 \times 1.5 \times 3 \mathrm{~mm}^{3}$. Proton magnetic resonance spectroscopic imaging $\left({ }^{1} \mathrm{HMRS}\right)$ spectra were obtained through the Spectroscopy SV software version 1.0 on Leonardo Workstation (Siemens, Erlangen, Germany).

${ }^{1}$ HMRS and diffusion coefficients were assessed according to postmenstrual ages of the patients.

Two expert pediatric neuroradiologists (CA and CC), who were blinded to the clinical history and to the developmental outcome of the patients (although they were informed about gestational age, it was essential for the evaluation of developmental stages at the scan), separately evaluated all the MRI examinations including visual analysis of severity and distribution of eventual MRI lesions, mean diffusivity of semioval centre and lenticular nuclei, and area under the curve of basal ganglia $N$-acetylaspartate (NAA) at ${ }^{1} \mathrm{HMRS}$. The differences in the evaluations of nonquantitative parameters were then resolved by consensus between the two neuroradiologists.

The severity of MRI lesions was also systematically scored through Bednarek severity scores (a previously published semiquantitative system that considered regional subscores for basal ganglia, white matter, cortex, brainstem, and cerebellum and a global score resulting from the sum of the subscores; see Table 2). ${ }^{[3]}$

The mean diffusivity of semioval centre and lenticular nuclei through DWI was available for 27/29 patients. ${ }^{1}$ HMRS was performed in $24 / 29$ patients.

All patients underwent periodical neurodevelopmental evaluations and Griffiths Mental Development Scales-third edition (GMDS-III) were used to assess neurocognitive outcome at the age of 24 months. Of the 29 patients, 28 underwent GMDS-III also at the age of 12 months. GMDS-III was administered by an expert infantile neuropsychologist (AR) who was blinded to MRI features of the patients. The developmental outcome was considered unfavorable if GMDS-III global quotient was $<85$.

The statistic analysis was performed using Stata Statistical software version 8.1, College Station, USA.

The negative and positive predictive values of early brain MRI were calculated. The Mann-Whitney $U$ test was used to evaluate differences in neuromotor and cognitive outcome between patients with no/minimally abnormal brain MRI (Group A-Bednarek severity global score between 48 and 55) and patients with moderate or severe neuroradiological abnormalities (Group B-Bednarek severity global score between 56 and 186).
The correlations between different neuroradiological predictors (Bednarek severity global scores and subscores, mean diffusivity of semioval centre and lenticular nuclei, and area under the curve of basal ganglia NAA at ${ }^{1} \mathrm{HMRS}$ ) and neuromotor and cognitive outcome (GMDS-III scores at 12 and 24 months) in the whole sample were assessed through Spearman's coefficient. Written informed consent was obtained from the parents of all selected patients and the study was approved by the ethics committee of Sapienza Università di Roma and Umberto I-Policlinico di Roma.

\section{Results}

In the selected temporal range (January 1, 2011December 31, 2015), 61 newborns with hypoxic-ischemic encephalopathy underwent therapeutic hypothermia in our institution. Twenty-nine consecutive patients (15 men and 14 women) with all the required criteria were recruited for this study. Two newborns who did not complete therapeutic hypothermia because of complications, three newborns who died before MRI, sixteen newborns who did not reach 24 months of follow-up at the moment of the retrospective analysis, and eleven newborns who were lost in follow-up were excluded from this study.

Table 1 summarizes auxologic features, Apgar scores, Sarnat stages, arterial blood test values, and amplitudeintegrated electroencephalography (aEEG) severity in the neonatal age of all selected patients, whereas neuroradiological and neurocognitive scores are reported, respectively, in Tables 2 and 3.

The mean age at MRI was $5.7 \pm 3.7$ days after birth (range 1-20 days). At visual evaluation of MRI, brain lesions were prominently ischemic [Table 2] with the involvement of different sites mainly including basal ganglia (nine patients) and periventricular area (nine patients). Intraventricular hemorrhages were seen in two patients (Patients 7 and 19) [Table 2]. No brain lesions were seen in 13 patients (Patients 4, 5, 8, 9, 10, 12, 13, $14,18,23,24,27$, and 29) [Table 2]. Group A included $17 / 29$ subjects (58.6\%: 10 men and 7 women) whereas Group B included 12/29 subjects (41.4\%: 5 men and 7 women).

The correlation between Bednarek severity global score and GMDS-III scores showed that early post-cooling brain MRI had a negative predictive value of $93.75 \%$ at 12 months and $100 \%$ at 24 months and a positive predictive value of $36.36 \%$ at 12 months and $50 \%$ at 24 months for an unfavorable developmental outcome. 


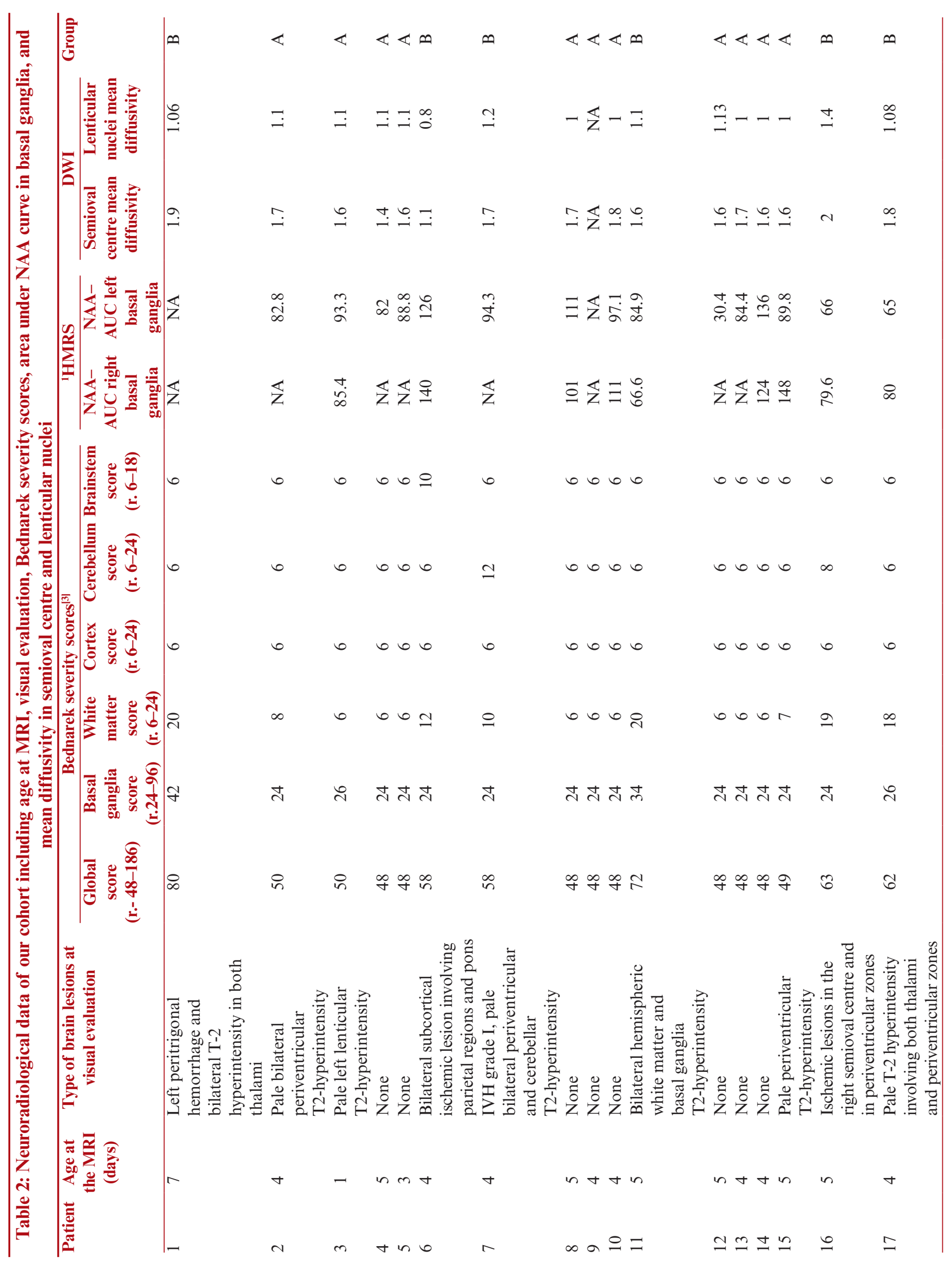




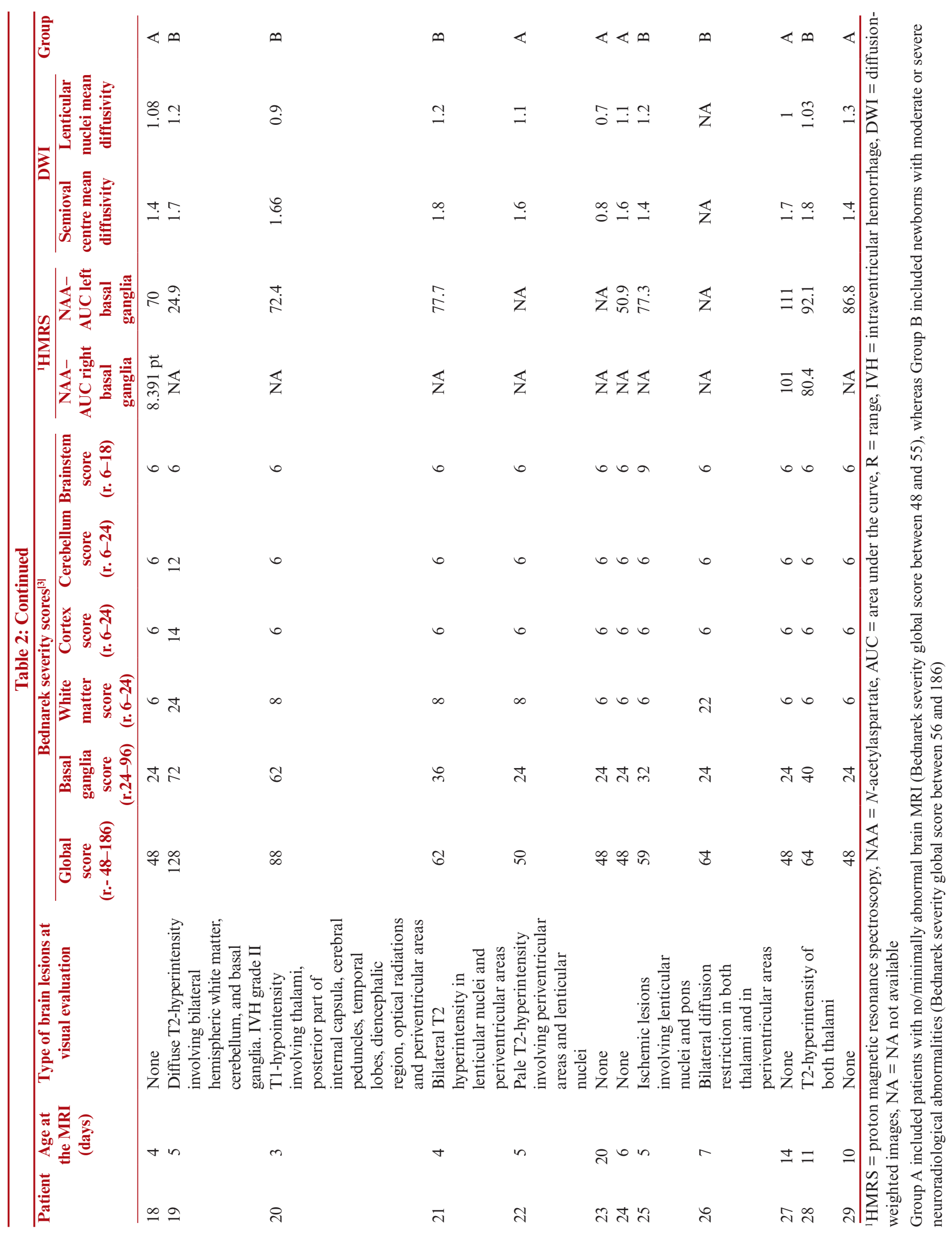




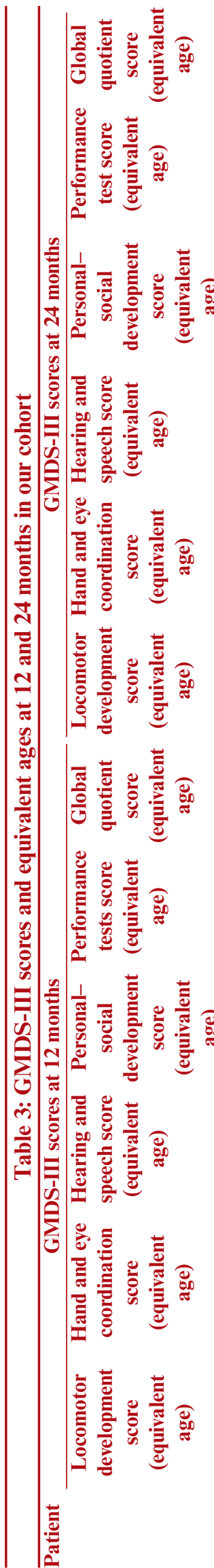

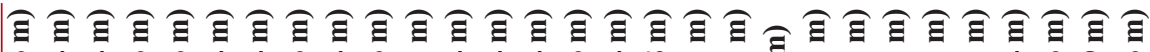

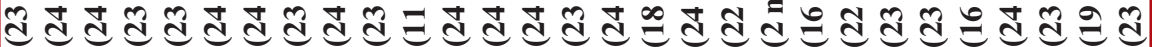

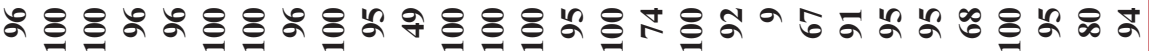

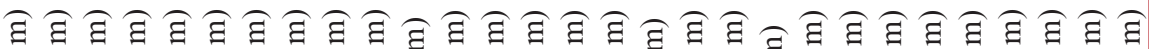

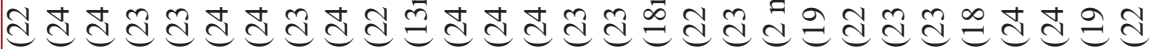

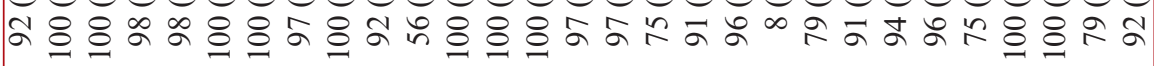

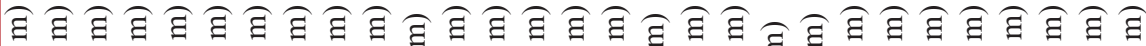

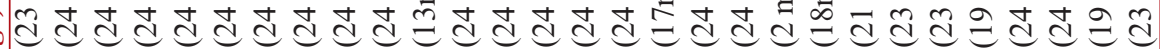

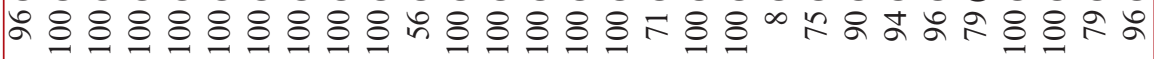

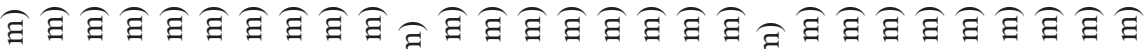

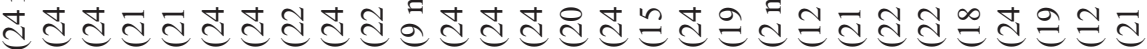

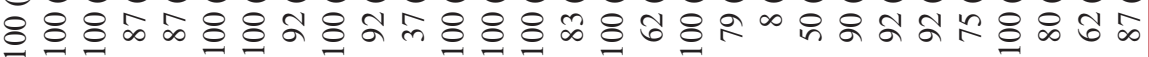

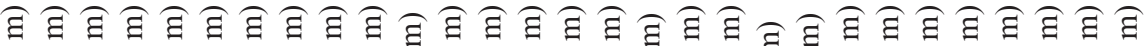

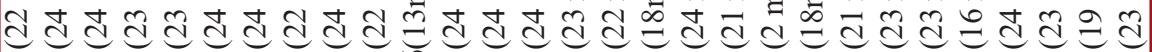

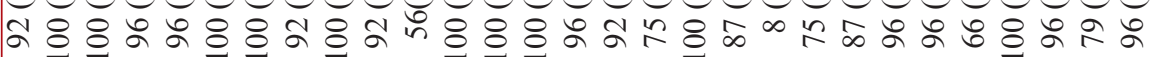

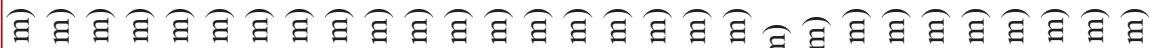

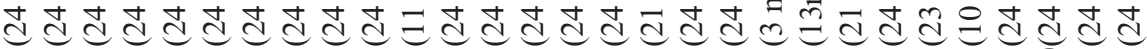

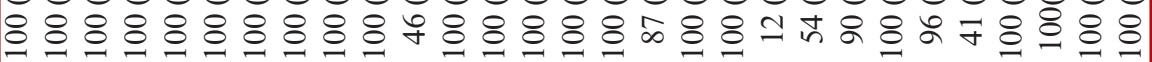

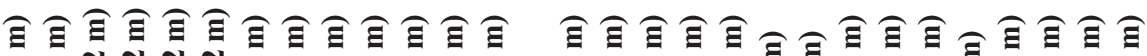

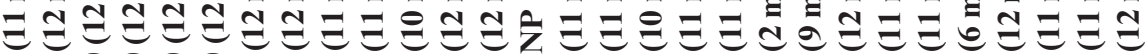

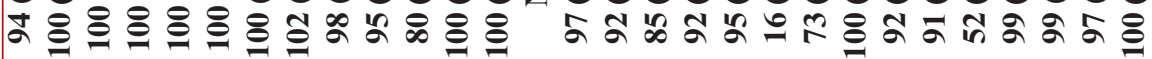

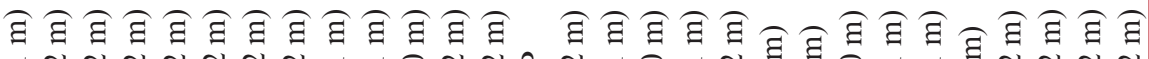

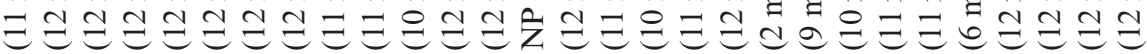

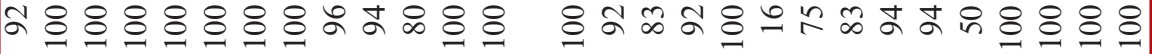

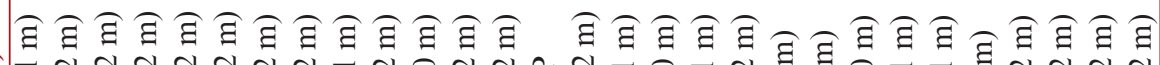

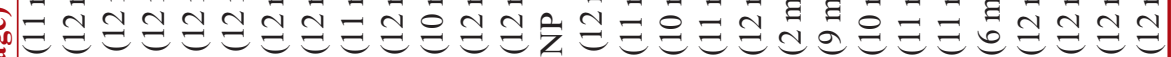

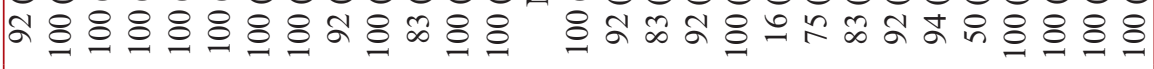

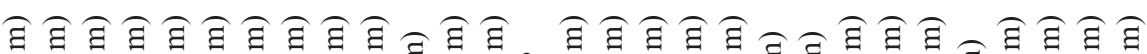

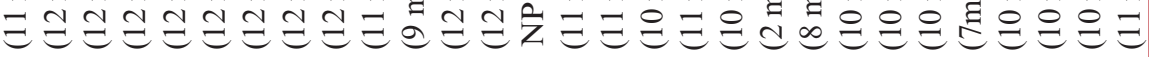

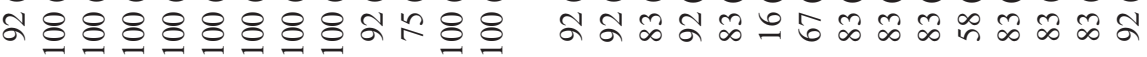

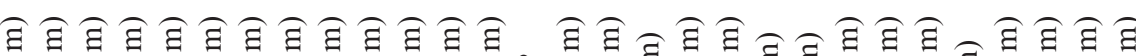

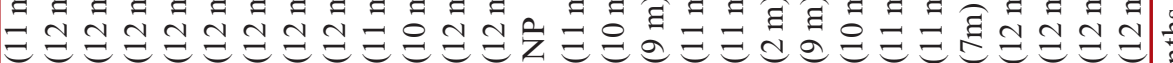

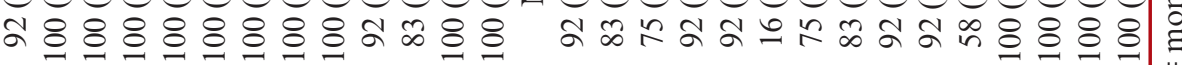

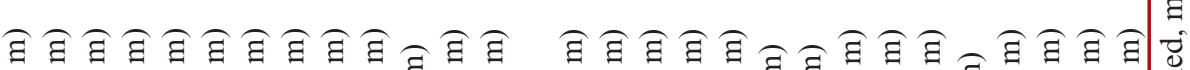

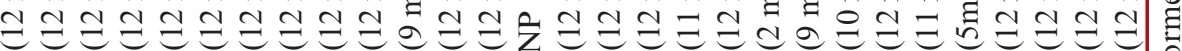

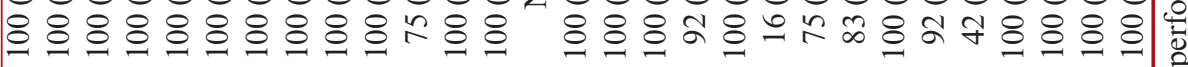




\begin{tabular}{|c|c|c|c|}
\hline General features & Group A & Group B & $P$ value \\
\hline Number of patients & 17 & 12 & NA \\
\hline Sex Males & 10 & 5 & $0.362^{*}$ \\
\hline Females & 7 & 7 & \\
\hline $\begin{array}{l}\text { Mean gestational age } \\
\text { (median gestational age) }\end{array}$ & $\begin{array}{c}39.74 \pm 1.19 \mathrm{w} \\
(M=40 ; \operatorname{Min}=37,7 ; \operatorname{Max}=42,4)\end{array}$ & $\begin{array}{c}38.05 \pm 2.01 \mathrm{w} \\
(M=38 ; \operatorname{Min}=34 ; \operatorname{Max}=40,5)\end{array}$ & 0.0339 \\
\hline $\begin{array}{l}\text { Mean birthweight } \\
\text { (median birthweight) }\end{array}$ & $\begin{array}{c}3239.70 \pm 470.47 \mathrm{~g} \\
(M=3200 ; \operatorname{Min}=2480 ; \operatorname{Max}=4020)\end{array}$ & $\begin{array}{c}2938.33 \pm 424.23 \mathrm{~g} \\
(M=2925 ; \operatorname{Min}=2290 ; \operatorname{Max}=3820)\end{array}$ & 0.0881 \\
\hline $\begin{array}{l}\text { Mean Apgar score } \\
\text { (median Apgar score) } \\
1^{\prime}\end{array}$ & $\begin{array}{c}2.52 \pm 1.58 \\
(M=2 ; \operatorname{Min}=0 ; \operatorname{Max}=6)\end{array}$ & $\begin{array}{c}2.66 \pm 1.96 \\
(M=3 ; \operatorname{Min}=0 ; \operatorname{Max}=5)\end{array}$ & 0.8396 \\
\hline $\begin{array}{l}\text { Mean Apgar score } \\
\text { (median Apgar score) } \\
5^{\prime}\end{array}$ & $\begin{array}{c}5.66 \pm 1.39 \\
(M=5 ; \operatorname{Min}=4 ; \operatorname{Max}=8)\end{array}$ & $\begin{aligned} & 5.75 \pm 2.00 \\
(M= & 6,5 ; \operatorname{Min}=3 ; \operatorname{Max}=8)\end{aligned}$ & 0.9801 \\
\hline GMDS-III at 12 months & $\begin{array}{c}\text { Group A } \\
\text { mean scores at } 12 \text { months } \\
\text { (median sores at } 12 \text { months) }\end{array}$ & $\begin{array}{c}\text { Group B } \\
\text { mean scores at } \mathbf{1 2} \text { months } \\
\text { (median scores at } \mathbf{1 2} \text { months) }\end{array}$ & $P$ value \\
\hline Locomotor development score & $\begin{array}{c}97.62 \pm 4.45 \\
(M=100 ; \operatorname{Min}=86 ; \operatorname{Max}=100)\end{array}$ & $\begin{aligned} 82.54 & \pm 28.84 \\
(M=100 ; \operatorname{Min} & =16 ; \operatorname{Max}=100)\end{aligned}$ & 0.2708 \\
\hline $\begin{array}{l}\text { Hand and eye coordination } \\
\text { score }\end{array}$ & $\begin{array}{c}95.93 \pm 5.22 \\
(M=100 ; \operatorname{Min}=83 ; \operatorname{Max}=100)\end{array}$ & $\begin{array}{c}79.45 \pm 24.76 \\
(M=83 ; \operatorname{Min}=16 ; \operatorname{Max}=100)\end{array}$ & 0.0196 \\
\hline Hearing and speech score & $\begin{array}{c}93.25 \pm 7.05 \\
(M=92 ; \operatorname{Min}=83 ; \operatorname{Max}=100)\end{array}$ & $\begin{array}{c}75.63 \pm 22.99 \\
(M=83 ; \operatorname{Min}=16 ; \operatorname{Max}=100)\end{array}$ & 0.0053 \\
\hline $\begin{array}{l}\text { Personal-social development } \\
\text { score }\end{array}$ & $\begin{array}{c}97.06 \pm 5.02 \\
(M=100 ; \operatorname{Min}=83 ; \operatorname{Max}=100)\end{array}$ & $\begin{array}{c}81 \pm 26.29 \\
(M=92 ; \operatorname{Min}=16 ; \operatorname{Max}=100)\end{array}$ & 0.0294 \\
\hline Performance tests score & $\begin{array}{c}96.75 \pm 5.03 \\
(M=100 ; \operatorname{Min}=83 ; \operatorname{Max}=100)\end{array}$ & $\begin{array}{c}81 \pm 26.33 \\
(M=92 ; \operatorname{Min}=16 ; \operatorname{Max}=100)\end{array}$ & 0.0435 \\
\hline Global quotient & $\begin{array}{c}96.31 \pm 4.86 \\
(M=98.5 ; \operatorname{Min}=83 ; \operatorname{Max}=100)\end{array}$ & $\begin{array}{c}80.27 \pm 25.62 \\
(M=92 ; \operatorname{Min}=16 ; \operatorname{Max}=100)\end{array}$ & 0.0199 \\
\hline GMDS-III at 24 months & $\begin{array}{c}\text { Group A } \\
\text { mean scores at } 24 \text { months } \\
\text { (median sores at } 24 \text { months) }\end{array}$ & $\begin{array}{c}\text { Group B } \\
\text { mean scores at } 24 \text { months } \\
\text { (median sores at } 24 \text { months) }\end{array}$ & $P$ value \\
\hline Locomotor development score & $\begin{array}{c}99.76 \pm 0.97 \\
(M=100 ; \operatorname{Min}=96 ; \operatorname{Max}=100)\end{array}$ & $\begin{aligned} 78.33 & \pm 31.32 \\
(M=100 ; \operatorname{Min} & =12 ; \operatorname{Max}=100)\end{aligned}$ & 0.0147 \\
\hline $\begin{array}{l}\text { Hand and eye coordination } \\
\text { score }\end{array}$ & $\begin{array}{c}97.05 \pm 3.32 \\
(M=96 ; \operatorname{Min}=90 ; \operatorname{Max}=100)\end{array}$ & $\begin{array}{c}77.5 \pm 26.05 \\
(M=83 ; \operatorname{Min}=8 ; \operatorname{Max}=100)\end{array}$ & 0.0069 \\
\hline Hearing and speech score & $\begin{array}{c}93.64 \pm 6.91 \\
(M=92 ; \operatorname{Min}=80 ; \operatorname{Max}=100)\end{array}$ & $\begin{aligned} 72.75 & \pm 30.11 \\
(M=77 ; \operatorname{Min} & =8 ; \operatorname{Max}=100)\end{aligned}$ & 0.0853 \\
\hline $\begin{array}{l}\text { Personal-social development } \\
\text { score }\end{array}$ & $\begin{array}{c}98.58 \pm 2.89 \\
(M=100 ; \operatorname{Min}=90 ; \operatorname{Max}=100)\end{array}$ & $\begin{array}{c}80.33 \pm 27.173 \\
(M=87.5 ; \operatorname{Min}=8 ; \operatorname{Max}=100)\end{array}$ & 0.0182 \\
\hline Performance tests score & $\begin{array}{c}96.88 \pm 3.68 \\
(M=98 ; \operatorname{Min}=90 ; \operatorname{Max}=100)\end{array}$ & $\begin{array}{c}79.75 \pm 26.45 \\
(M=85.5 ; \operatorname{Min}=8 ; \operatorname{Max}=100)\end{array}$ & 0.0303 \\
\hline Global quotient & $\begin{array}{c}97.17 \pm 2.94 \\
(M=96 ; \operatorname{Min}=91 ; \operatorname{Max}=100)\end{array}$ & $\begin{aligned} 77.91 & \pm 27.46 \\
(M=86 ; & \text { Min }=9 ; \operatorname{Max}=100)\end{aligned}$ & 0.0589 \\
\hline
\end{tabular}

NA $=$ not applicable, $\mathrm{w}=$ weeks, $\mathrm{g}=$ grams, $\mathrm{M}=$ median, Min $=$ minimum, Max $=$ maximum, GMDS-III $=$ Griffiths Mental Development Scales-III rd edition

*Chi-squared test

The Mann-Whitney $U$ test showed a significantly higher mean gestational age in Group A than in Group B and a higher birthweight (even if not statistically significant), whereas no significant differences were found in terms of Apgar score [Table 4]. Children belonging to Group
A had higher mean values of global quotient, subitem scores, and equivalent ages at GMDS-III than children belonging to Group B [Table 4]. Patients of Group A had also higher mean area under NAA curve in basal ganglia than members of Group B (106.22 \pm 24.70 vs. 
$89.32 \pm 28.92$ in the right side and $86.60 \pm 25.35$ in the left side) with no relevant differences in mean diffusivity in the analyzed structures.

The analysis of the whole sample through Spearman's coefficient showed a weak correlation between all Bednarek severity scores and GMDS-III scores both at the age of 12 and 24 months [Table 5]. Among severity regional subscores, basal ganglia score had the strongest correlation with both GMDS-III global quotient and subitem scores [Table 5]. A strong correlation was also recorded between area under NAA curve in basal ganglia and both GMDS-III global quotient and subitem scores with higher mean Spearman's coefficients at the age of 12 months than at the age of 24 months [Table 5]. None of the patients had detectable lactate peaks at ${ }^{1} \mathrm{HMRS}$. No significant correlations were found between mean diffusivity data and neuropsychological indices [Table 5].

\section{Discussion}

The results of our study highlight the following [Tables 4 and 5]: (a) a normal early post-cooling brain MRI is strongly associated with a favorable cognitive and motor outcome (high negative predictive value for psychomotor delay both at the age of 12 and 24 months); (b) the presence of abnormalities at early post-cooling brain MRI is not necessarily related with an unfavorable outcome; and (c) structural and spectroscopic abnormalities in basal ganglia at early post-cooling brain MRI can be considered as a reliable predictor for an adverse motor and cognitive outcome, whereas structural lesions and diffusion abnormalities involving other cerebral sites (including cortex, cerebellum, brainstem, or white matter) often fail to predict developmental delay.

The high negative predictive value for a favorable developmental outcome of early post-cooling brain MRI, in our sample, agreed with similar previously published data by Charon et al. ${ }^{[6]}$ and Kasdorf et al. ${ }^{[14]}$ As additional points of strength, our study includes a more homogenous and adequate measurement of cognitive outcome for the considered age-range (Charon et al. used Brunet Lezine Revised Scale up to 30 months and, for children between 30 and 41 months, neurological examination only) and a large number of tested neuroradiological parameters (both the aforementioned studies did not include spectroscopic data). ${ }^{[6,14]}$ A lower negative predictive value $(74 \%)$ was reported in older newborns (mean age at MRI of 8 days) by Rollins et al. ${ }^{[10]}$ and Chalak et al. ${ }^{[1]}$ These authors observed a significant quote of cooled patients with normal or minimally altered
MRI who developed moderate $(20 \%-70 \%$ of patients) or severe developmental delay ( $6 \%$ of patients). ${ }^{[10,11]}$ These conflicting results suggest caution in the parental counseling after a normal early post-cooling MRI and impose periodical developmental evaluations beyond the first two years after birth. ${ }^{[6,7,9-11,14,15]}$ This approach could be useful for the choice of the best timing for performing subsequent MRI in patients with a normal early MRI and without progress in developmental milestones despite an optimal cooling and rehabilitative management. ${ }^{[11]}$

In our sample, the presence of moderate or severe MRI abnormalities after cooling (patients belonging to Group B) scarcely correlated with an unfavorable developmental outcome. The positive predictive values of MRI at 12 and 24 months were lower than in previous studies. ${ }^{[9-11,13]}$ Single case inspection confirmed a remarkable interindividual variability in neuromotor and cognitive outcome independently from neuroradiological pattern. For example, Patient 19 [see Figure 1 in Supplementary Material for MRIs] had the highest Bednarek severity global score of our cohort (128/186), but he indicated only a mild delay at GMDS-III (at 24 months general quotient was 92 with an equivalent age of 22 months). These results can be interpreted through the frequent transient nature of several signal MRI abnormalities in the early postcooling stages (especially the ones following less severe ischemic insults that are more responsive to therapeutic hypothermia). Another possible explanation is given by the assumption that prognostic meaning of MRI abnormalities varies according to the site and the extension of the lesions regardless of hypothermia as it was reported by Cheong et al. ${ }^{[9]}$ and Rutherford et al. ${ }^{[13]}$ in representative subgroups from two large controlled randomized trials.

Our study confirmed, according to the data of the literature the relevant role of basal ganglia involvement in ischemic perinatal damages as a reliable predictor of unfavorable outcome after cooling. ${ }^{[13-15]}$ These data also showed that the lack of neuroradiological abnormalities in basal ganglia can be considered as a good marker of the neuroprotective action of therapeutic hypothermia against reperfusion damages. ${ }^{[13-16]}$ Lesions involving basal ganglia in hypoxic-ischemic encephalopathy results in an impaired regulation of motor control, acquisition of language abilities, reasoning, and rewardbased learning during the development. ${ }^{[17]}$ Kasdorf et al. ${ }^{[14]}$ reported that newborns with basal ganglia lesions after therapeutic hypothermia presented with a more frequent necessity of neonatal cardiopulmonary resuscitation, a more persistent severe acidosis, more 


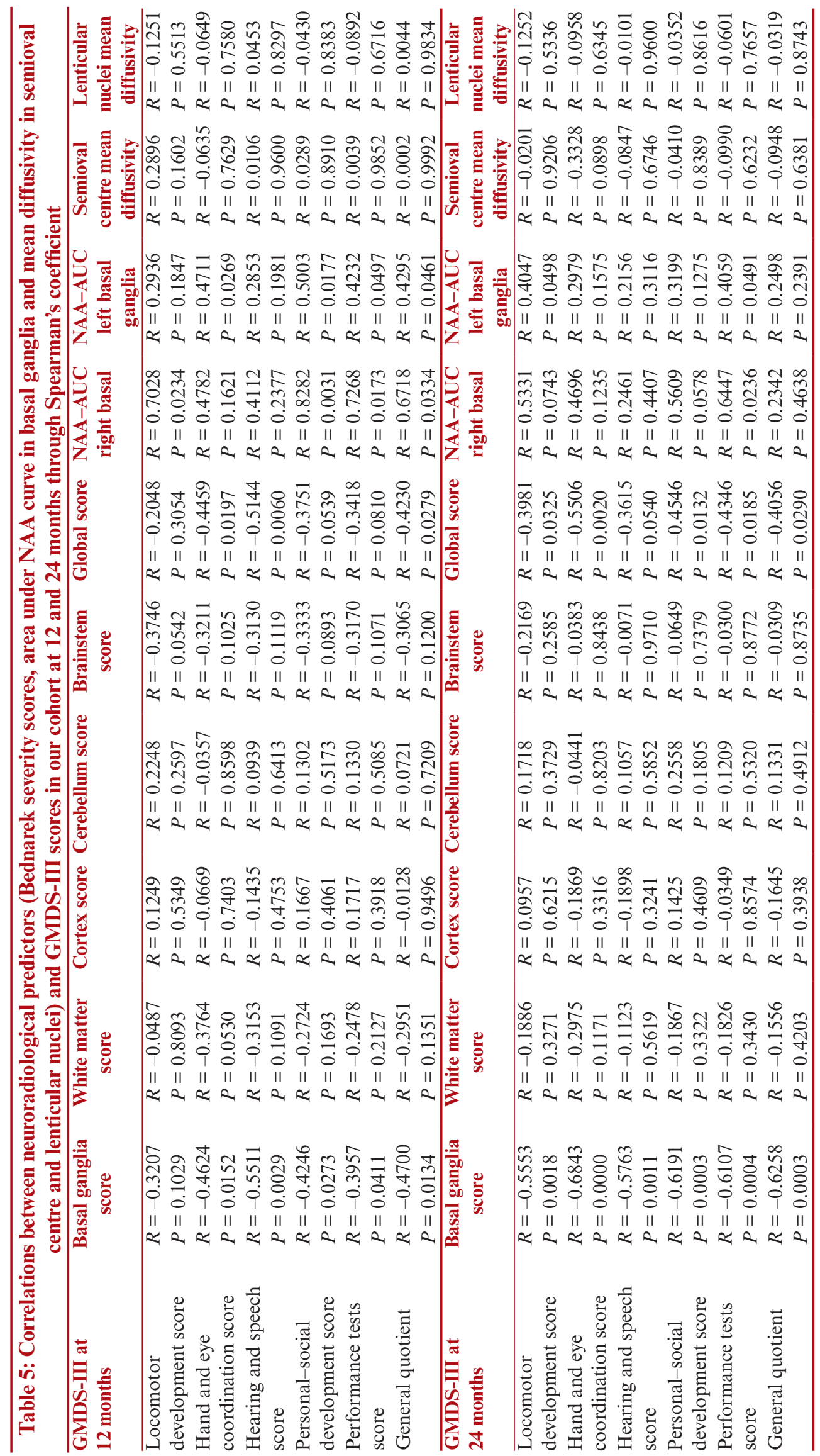




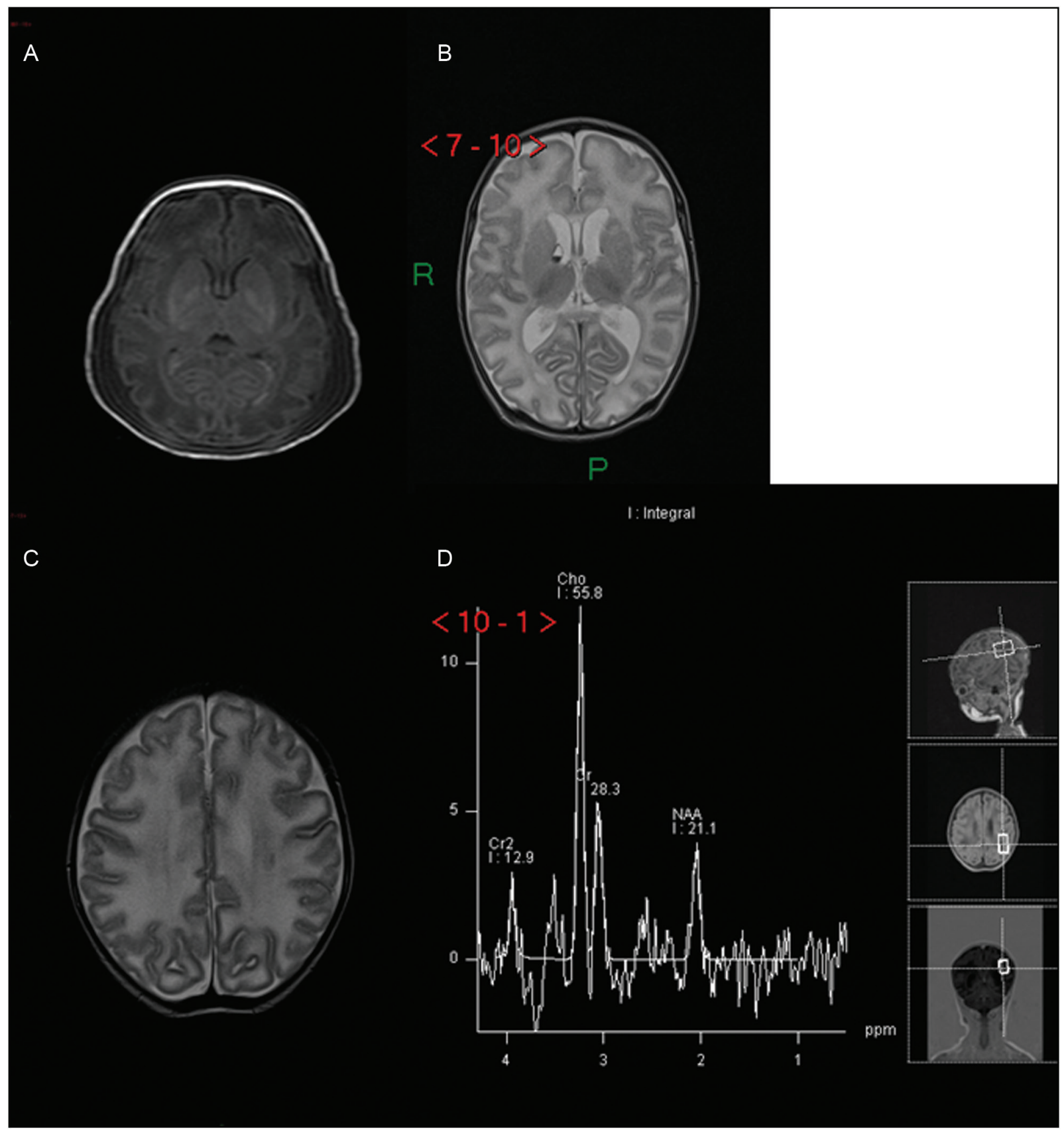

Figure 1: (A) T1-weighted axial image showing hyperintensity on basal ganglia and thalami. (B-C) T2-weighted axial images showing diffuse hyperintensity involving bilateral hemispheric white matter and basal ganglia. IVH grade II is seen on the right frontal horn of lateral ventricle. (D) Spectroscopy sequence obtained on the left basal ganglia

severe electroencephalographic abnormalities, a higher quote of encephalopathic features, and a more frequent abnormal developmental outcome than subjects with normal MRI and subjects with hippocampal injuries. Moreover, Alderliesten et al. ${ }^{[15]}$ showed that low apparent coefficient diffusion values and high lactate/NAA ratios of basal ganglia at ${ }^{1} \mathrm{HMRS}$ were associated with a negative outcome at 24 months. No abnormalities of lactate were seen in our patients (none had advanced neuronal necrosis in the damaged areas because of the restricted temporal window between ischemic processes, cooling, and MRI), whereas area under the curve of NAA in basal ganglia represented a more useful prognostic index. 
The lack of strong correlations between neurocognitive outcome and structural and diffusion abnormalities in cerebral structures other than basal ganglia partially agrees with previously reported data. Cheong et al. ${ }^{[13]}$ reported a relatively low negative predictive value (between 54\% and 63\%) for lesions involving posterior limbs of internal capsula, white matter, and cortical grey matter. Charon et al. ${ }^{[6,7]}$ reported that apparent coefficient diffusion measurements in posterior white matter, semioval centers, and posterior limbs of internal capsula added little to simple visual analysis of MRI for prognostic evaluations. Mean diffusivity and its variations are probably more reliable as a short-term index for the measurement of therapeutic response to hypothermia than for the prediction of long-term neurocognitive development. ${ }^{[3]}$

The limitations of our study include (a) its retrospective nature; (b) the limited number of patients in the analyzed sample; (c) the variable timing for performing MRI; (d) the semiquantitative tool that was used for the evaluation of severity of brain MRI lesions (Bednarek severity score allowed a systematic evaluation of all cerebral lesions but it has been previously used only in the original paper, that had a different design if compared with ours) ${ }^{[3]}$; (e) the technical limitations (better results for the detection of subtle lesions could be obtained with high-field 3T-MRI or functional MRI studies); (f) the selection bias that resulted from the exclusion of cases who did not reach 24 months of follow-up at the moment of the retrospective analysis (the minimum age that was considered to evaluate the progression of GMDS-III scores).This criterion could have facilitated the selection of less-severe cases because of the exclusion of newborns who died after hypothermia and of the patients who were lost in follow-up.

\section{Conclusion}

This study suggests that a normal MRI in early postcooling phases is strongly associated with a favorable developmental outcome and confirms the negative prognostic value of basal ganglia lesions. Future trials should be focused on the definition of the optimal timing of MRI investigations in order to address the treatment protocols and the post-intensive care rehabilitation strategies.

\section{Ethical policy and institutional review board statement}

The study was approved by the ethics committee of Sapienza Università di Roma and Umberto I-Policlinico di Roma.

\section{Financial support and sponsorship}

Nil.

\section{Conflicts of interest}

There are no conflicts of interest.

\section{REFERENCES}

1. Shankaran S, McDonald SA, Laptook AR, Hintz SR, Barnes PD, Das A, et al.; Eunice Kennedy Shriver National Institute of Child Health and Human Development Neonatal Research Network. Neonatal magnetic resonance imaging pattern of brain injury as a biomarker of childhood outcomes following a trial of hypothermia for neonatal hypoxic-ischemic encephalopathy. J Pediatr 2015;167:987-93.e3.

2. Rutherford M, Srinivasan L, Dyet L, Ward P, Allsop J, Counsell $\mathrm{S}$, et al. Magnetic resonance imaging in perinatal brain injury: clinical presentation, lesions and outcome. Pediatr Radiol 2006;36:582-92

3. Bednarek N, Mathur A, Inder T, Wilkinson J, Neil J, Shimony J. Impact of therapeutic hypothermia on MRI diffusion changes in neonatal encephalopathy. Neurology 2012;78:1420-7.

4. Massaro AN, Evangelou I, Fatemi A, Vezina G, Mccarter R, Glass $\mathrm{P}$, et al. White matter tract integrity and developmental outcome in newborn infants with hypoxic-ischemic encephalopathy treated with hypothermia. Dev Med Child Neurol 2015;57:441-8.

5. Bonifacio SL, Saporta A, Glass HC, Lee P, Glidden DV, Ferriero DM, et al. Therapeutic hypothermia for neonatal encephalopathy results in improved microstructure and metabolism in the deep gray nuclei. AJNR Am J Neuroradiol 2012;33:2050-5.

6. Charon V, Proisy M, Bretaudeau G, Bruneau B, Pladys P, Beuchée A, et al. Early MRI in neonatal hypoxic-ischaemic encephalopathy treated with hypothermia: prognostic role at 2-year follow-up. Eur J Radiol 2016;85:1366-74.

7. Charon V, Proisy M, Ferré JC, Bruneau B, Tréguier C, Beuchée A, et al. Comparison of early and late MRI in neonatal hypoxic-ischemic encephalopathy using three assessment methods. Pediatr Radiol 2015;45:1988-2000.

8. Shankaran S, Barnes PD, Hintz SR, Laptook AR, Zaterka-Baxter KM, McDonald SA, et al. Brain injury following trial of hypothermia for neonatal hypoxicischemic encephalopathy. Arch Dis Child Fetal Neonatal Ed 2012;97:F398-404.

9. Rutherford M, Ramenghi LA, Edwards AD, Brocklehurst P, Halliday $\mathrm{H}$, Levene $\mathrm{M}$, et al. Assessment of brain tissue injury after moderate hypothermia in neonates with hypoxicischaemic encephalopathy: a nested substudy of a randomised controlled trial. Lancet Neurol 2010;9:39-45.

10. Rollins N, Booth T, Morriss MC, Sanchez P, Heyne R, Chalak L. Predictive value of neonatal MRI showing no or minor degrees of brain injury after hypothermia. Pediatr Neurol 2014;50:447-51.

11. Chalak LF, DuPont TL, Sánchez PJ, Lucke A, Heyne RJ, Morriss MC, et al. Neurodevelopmental outcomes after hypothermia therapy in the era of Bayley-III. J Perinatol 2014;34:629-33.

12. Rutherford M, Counsell S, Allsop J, Boardman J, Kapellou O, Larkman $\mathrm{D}$, et al. Diffusion-weighted magnetic resonance imaging in term perinatal brain injury: a comparison with site of lesion and time from birth. Pediatrics 2004;114:1004-14. 
13. Cheong JL, Coleman L, Hunt RW, Lee KJ, Doyle LW, Inder TE, et al.; Infant Cooling Evaluation Collaboration. Prognostic utility of magnetic resonance imaging in neonatal hypoxic-ischemic encephalopathy: substudy of a randomized trial. Arch Pediatr Adolesc Med 2012;166:634-40.

14. Kasdorf E, Engel M, Heier L, Perlman JM. Therapeutic hypothermia in neonates and selective hippocampal injury on diffusion-weighted magnetic resonance imaging. Pediatr Neurol 2014;51:104-8.

15. Alderliesten T, de Vries LS, Staats L, van Haastert IC, Weeke L, Benders MJ, et al. MRI and spectroscopy in (near) term neonates with perinatal asphyxia and therapeutic hypothermia. Arch Dis Child Fetal Neonatal Ed 2017;102:F147-52.

16. Faingold R, Cassia G, Morneault L, Saint-Martin C, Sant'Anna G. Basal ganglia perfusion using dynamic color Doppler sonography in infants with hypoxic ischemic encephalopathy receiving therapeutic hypothermia: a pilot study. Quant Imaging Med Surg 2016;6:510-4.

17. Leisman G, Braun-Benjamin O, Melillo R. Cognitive-motor interactions of the basal ganglia in development. Front Syst Neurosci 2014;8:16. 
(C) 2019. This work is published under

https://creativecommons.org/licenses/by-nc-sa/4.0/(the "License").

Notwithstanding the ProQuest Terms and Conditions, you may use this content in accordance with the terms of the License. 